\title{
Re-emergence of Cassava Brown Streak Disease in Uganda
}

T. Alicai and C. A. Omongo, Namulonge Crops Resources Research Institute, P.O. Box 7084, Kampala, Uganda; M. N. Maruthi and R. J. Hillocks, Natural Resources Institute, University of Greenwich, Chatham Maritime, Kent ME4 4TB, UK; Y. Baguma, R. Kawuki, A. Bua, and G. W. Otim-Nape, Namulonge Crops Resources Research Institute, P.O. Box 7084, Kampala, Uganda; and J. Colvin, Natural Resources Institute, University of Greenwich, Chatham Maritime, Kent ME4 4TB, UK

\begin{abstract}
Alicai, T., Omongo, C. A., Maruthi, M. N., Hillocks, R. J., Baguma, Y., Kawuki, R., Bua, A., Otim-Nape, G. W., and Colvin, J. 2007. Re-emergence of cassava brown streak disease in Uganda. Plant Dis. 91:24-29.

During November 2004, veinal chlorosis on mature cassava leaves, typical of cassava brown streak disease (CBSD), was observed at Mukono in central Uganda. Five out of 11 cultivars at the site showed CBSD symptoms (incidence range 4 to 64\%). In a survey of farmers' fields, CBSD was observed in Wakiso and Mukono districts. Incidence of cassava mosaic disease was also recorded and averaged $60 \%$ for landraces (range 16.7 to 100\%) and 20\% for resistant varieties (range 0 to $65 \%$ ). Leaf samples of plants with CBSD symptoms produced an amplicon of 222 bp using reverse transcription-polymerase chain reaction with primers that amplify a fragment of the coat protein (CP) gene of Cassava brown streak virus. Sequence comparisons based on the amplified CP gene fragment indicated that the isolates have 77 to $82.9 \%$ nucleotide and 43.9 to $56.8 \%$ amino acid identity with those from Mozambique and Tanzania. There was 95.9 to $99.5 \%$ nucleotide and 85.1 to $90.5 \%$ amino acid identity among the Ugandan isolates. These results confirm the re-emergence of CBSD in Uganda after it was first observed in the 1930s in cassava introduced from Tanzania and controlled by eradication. Prior to this report, CBSD was known to be restricted to the coastal lowlands of East Africa.
\end{abstract}

Additional keywords: Begomovirus, Bemisia tabaci, CMD

Cassava brown streak disease (CBSD) is caused by Cassava brown streak virus (CBSV) (genus Ipomovirus, family Potyviridae) $(20,21)$. The disease affects the yield and quality of the tuberous roots of cassava (Manihot esculenta Crantz). There are a number of different symptoms in the CBSD syndrome. On leaves, the disease appears as a feathery chlorosis on either side of the smaller veins. There are several variants of this symptom, depending on cultivar, crop age, and weather conditions (10). Characteristic CBSD foliar symptoms normally occur only on mature leaves, and the young expanding leaves are symptomless (3). The economically damaging symptom occurs on the tuberous roots as a yellow/brown, corky necrosis in the starch-bearing tissues, and radial root constriction occurs in very severe infections. The necrosis begins as discrete areas, but in fully susceptible cultivars, it may affect most of the root, rendering the roots unfit for human consumption (8$10,24)$. The history and current knowledge

Corresponding author: T. Alicai

E-mail: talicai@naro-ug.org

Accepted for publication 22 August 2006.

DOI: 10.1094/PD-91-0024

(C) 2007 The American Phytopathological Society on CBSD have been reviewed by Hillocks and Jennings (8).

The disease was first reported and distinguished from cassava mosaic disease (CMD) in Tanzania during the 1930s (28). Soon after, the whitefly, Bemisia tabaci (Gennadius), was suggested as a possible vector (29). Successful transmission of CBSV by $B$. tabaci between cassava plants was achieved only recently in 2004 (19). Surveys for CBSD found the disease to be endemic in all East African coastal cassava-growing areas from Kenya to the Ruvuma River that marks the border between Tanzania and Mozambique $(8,10,11)$. It was reported to be widespread in coastal Kenya $(3,23)$ and in Mozambique where it was prevalent $(11,32)$. Recent surveys have confirmed that the disease occurs throughout the coastal strip of Lake Malawi (7,27). Symptoms resembling those of CBSD have been reported from Bas-Congo and Kinshasa Provinces of the Democratic Republic of Congo (18), but the virus has not been confirmed by diagnostics. The reasons for the restricted occurrence of CBSD, despite the distribution of B. tabaci throughout Africa and the considerable movement of cassava planting materials, remain unknown.

Early studies led to the observation that CBSD could be found inland from the East African coast up to an altitude of 1,000 m above sea level (masl) (24). Surveys con- ducted during the 1990s appeared to support that view $(10,16)$. Although cassava is widely grown at altitudes above 1,000 masl in Tanzania, Malawi, and Mozambique, CBSD has not been reported from these areas. A nationwide survey of Tanzania in 1993 and 1994 showed CMD and $B$. tabaci in all parts of the country, but CBSD was found only in the lowlands bordering the Indian Ocean and Lake Malawi (16). Wherever the disease has been reported to be endemic, occurrences were confined to altitudes below 1,000 masl, and incidence increased with decreasing altitude (11). However, it has been known for some time that CBSD symptoms can be expressed at altitudes greater than 1,000 masl when infected cuttings have been planted. This occurred in Uganda when infected material was taken from Tanzania in 1934, but the disease was eradicated by destroying all plants showing symptoms (12). From that time until 2004, CBSD has not been prevalent in Uganda, although CBSD-like symptoms were observed on a few cassava plants at one site in central Uganda in 1994 (33).

Here, we report a new outbreak of CBSD in Uganda and confirmation of the presence of CBSV by reverse transcription-polymerase chain reaction (RT-PCR) and nucleotide sequence analysis. CBSD is a major disease of cassava in eastern Africa, and because of its direct effect on the quality of tuberous roots, it constitutes a significant threat to food production. Our results highlight the possibility that other countries in the region previously unaffected by CBSD may be at risk of spread and increased prevalence of the disease.

\section{MATERIALS AND METHODS}

Source of test materials. Cassava plants showing typical CBSD foliar symptoms were observed in demonstration fields at Mukono Zonal Agricultural Research and Development Institute (ZARDI) situated near Kampala City on the northern shores of Lake Victoria in Uganda. Leaf samples were collected from two plants showing typical CBSD foliar symptoms on each of four cultivars being grown at the ZARDI and also from two farmers' fields elsewhere in Mukono and Wakiso districts. Leaves exhibiting the clearest CBSD foliar symptoms (chlorosis along the small veins) were collected, and 
these were often the lower mature or maturing leaves. Leaf samples were also collected from apparently CBSD-free plants. The samples were prepared and tested for the presence of CBSV using RT-PCR.

Extraction of RNA from cassava leaves. Total RNA was extracted from ca. $150 \mathrm{mg}$ of cassava leaf samples using the CTAB protocol originally described for DNA isolation by Lodhi et al. (17), but slightly modified by eluting samples in RNase-free water at the end of the protocol and treating with DNase (Ambion DNAfree, Austin, TX, USA). Yield and purity (from $A_{260} / A_{280}$ ratio) of RNA extracted were measured using a Pharmacia Biotech Ultrospec 3000 spectrophotometer.

cDNA synthesis and PCR amplification. cDNA was synthesized from ca. $3 \mu \mathrm{g}$ of genomic RNA in a $20-\mu$ l reaction mixture using SuperScript III reverse transcriptase primed with oligo(dT) ${ }_{20}$ (Invitrogen, Carlsbad, CA, USA). The CBSVspecific primers CBSV 10F: 5' ATC AGAATAGTGTGACTGCTGG $3^{\prime}$ and CBSV 11R: 5' CCACATTATTATCGT CACCAGG 3' (20) were used for PCR amplification of the cDNA template. The 50- $\mu$ l PCR reaction mix consisted of $5.0 \mu \mathrm{l}$ of $10 \times$ reaction buffer, $1.0 \mu \mathrm{l}$ of $10 \mathrm{mM}$ dNTPs, $10 \mu \mathrm{M}$ of each primer, $2.5 \mathrm{U}$ of Taq DNA polymerase (Invitrogen), $2.0 \mu \mathrm{l}$ of cDNA, and reactions were brought to volume with sterile water. Reactions were run in an Eppendorf Mastercycler under the following thermal cycling conditions: template cDNA denaturation at $94^{\circ} \mathrm{C}$ for 5 min, 35 cycles of $94^{\circ} \mathrm{C}$ for $30 \mathrm{~s}, 52^{\circ} \mathrm{C}$ for $30 \mathrm{~s}$, and $72^{\circ} \mathrm{C}$ for $1 \mathrm{~min}$, and ending with $72^{\circ} \mathrm{C}$ for $10 \mathrm{~min}$. Amplicons were separated on a $1 \%(\mathrm{wt} / \mathrm{vol})$ agarose gel containing $0.5 \mu \mathrm{g} / \mathrm{ml}$ ethidium bromide in $1 \times$ TAE buffer and viewed under UV light.

Cloning, sequence determination, and comparisons. PCR-amplified products were purified using the QIAquick Gel Extraction Kit (Qiagen, MD, USA), ligated to the pCR 2.1-TOPO vector using the TOPO TA Cloning Kit, and then used to transform One Shot TOP10 chemically competent Escherichia coli (Invitrogen). Recombinant plasmid DNA containing CBSV sequences were isolated using the QIAprep Spin Miniprep Kit (Qiagen) and confirmed by PCR. For each isolate, three independent clones were sequenced in both orientations using the M13 universal primers. Sequencing reactions were performed using the dideoxynucleotide chain termination procedure on an automated ABI 1377 DNA sequencer (Perkin Elmer, Foster City, CA, USA). Nucleotide sequences were assembled and compared using the CLUSTAL W (31) algorithm from the MegAlign software of the DNASTAR package (DNASTAR, Madison, WI, USA). Nucleotide sequences of Ugandan isolates (GenBank accession numbers DQ837302, DQ837303, DQ837304) were compared with the six published CBSV CP gene sequences that include two isolates from Mozambique (AF311053, AF311052) and four isolates from Tanzania (AY008442, AY008441, AY008440, AY007597).

Survey of CBSD in three districts. A total of 120 farmers' fields of cassava, 40 in each of Mukono, Wakiso, and Mayuge districts, were assessed during January 2005 to record the incidence and severity of CBSD, CMD, and whitefly numbers. Wakiso and Mayuge are to the west and east of Mukono, respectively, the latter being the district where the recent observation of plants with CBSD symptoms was first reported. In each district, 30 fields were assessed for aboveground symptoms and 10 fields for symptoms on roots. Fields were selected at regular intervals along major and feeder roads traversing the districts. The distance between sampled fields was about $7 \mathrm{~km}$ for aboveground symptoms and $21 \mathrm{~km}$ for symptoms on tuberous roots. Crops assessed for foliar symptoms were those planted 4 to 6 months previously. Only crops more than 10 months old were assessed for symptoms on tuberous roots.

Within each field sampled for aboveground symptoms, 30 plants of the dominant cultivar along two diagonals were examined in detail. Names of other cultivars found in each sampled field were also recorded. The presence or absence of CBSD symptoms on the leaves and stems was recorded for each plant using a scale of 1 (no symptoms) to 5 (defoliation, stem lesions, and dieback) (7). The same plants were also examined for CMD symptoms, recorded on a scale of 1 (no symptoms) to 5 (very severe leaf distortion, chlorosis, and stunting) (30). For CMD-affected plants, a distinction was made between recent infections by whiteflies and plants perpetuating CMD symptoms resulting from use of cuttings from CMD-affected plants as planting material. In plants newly infected by whiteflies, only the upper leaves show CMD symptoms, whereas in plants with cutting-derived infection, even early-formed leaves near the ground have symptoms. It is not yet clear whether such distinction is possible for CBSD-affected plants. The presence or absence of CBSD and CMD in neighboring fields and the proximity of such fields (adjacent, near [50 to $100 \mathrm{~m}$ ], far [>100 m], or none in site) relative to the sampled field were noted. In fields sampled for tuberous root symptoms, 10 plants were uprooted and the tuberous roots transversely sliced to check for root necrosis. Root symptoms were scored on a scale of 1 (no necrosis) to 5 ( $>25 \%$ necrotic) (7). The incidence of CBSD and CMD was calculated from the number of plants exhibiting CBSD (foliar) and CMD symptoms as a percentage of the total number of plants assessed in a field. In calculating mean severity per field, scores for symptomless plants were omitted. Numbers of adult whiteflies on the top five leaves of a representative shoot were counted on every other plant assessed for foliar symptoms; thus whitefly counts on a total of 15 plants per field were made. GPS readings of altitude, latitude, and longitude of each site were recorded.

\section{RESULTS}

Symptoms of CBSD. The most obvious symptom observed on infected cassava was yellow vein banding, expressed mainly on the lower, older leaves. The chlorosis occurred mainly along the secondary and tertiary veins, giving a feathery appearance, and was clearly different from CMD symptoms (Fig. 1). In addition, and distinct from CMD symptoms, the most symptomatic leaves had no or only mild leaf distortion regardless of the amount of chlorosis. Corky brownish necrosis of tuberous roots, the other symptom usually
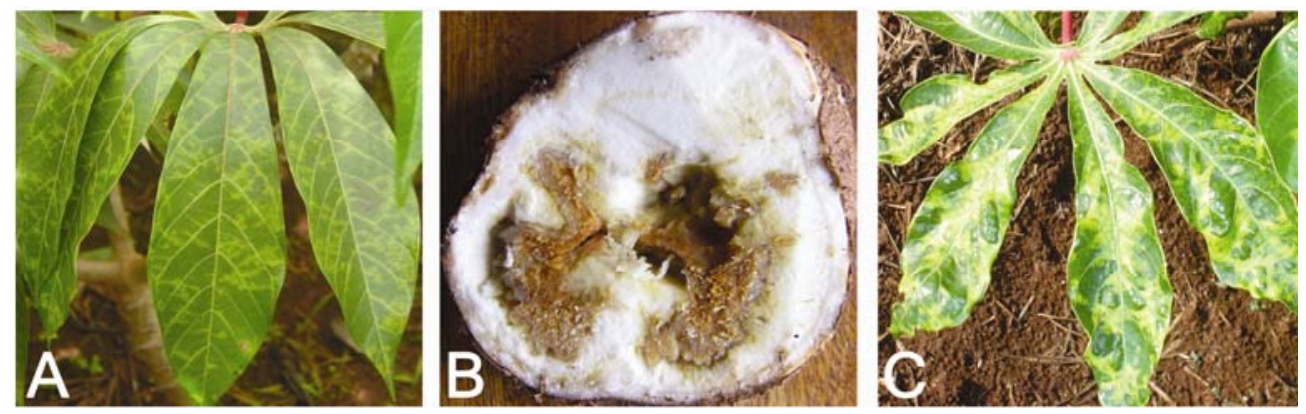

Fig. 1. A, Leaf of cassava brown streak disease (CBSD)-affected plant of cultivar TME 14 showing yellow vein banding along secondary and tertiary veins (feathery chlorosis). B, Root necrosis associated with CBSD in cultivar TME 204. C, Leaf of a cassava mosaic disease-affected plant of Ugandan landrace Nyaraboke showing leaf mosaic (normal green leaf tissue with interspersed discrete yellow areas) and leaf distortion. 
Table 1. Incidence and severity of cassava brown streak disease (CBSD), cassava mosaic disease (CMD), and whitefly numbers in plots at Mukono ${ }^{\mathrm{Z} A R D I}$ in Uganda

\begin{tabular}{|c|c|c|c|c|c|c|}
\hline \multirow[b]{2}{*}{ Cultivar } & \multirow[b]{2}{*}{ Number of plants } & \multicolumn{2}{|c|}{ CBSD (foliar) } & \multicolumn{2}{|c|}{ CMD } & \multirow[b]{2}{*}{ Adult whiteflies $^{\mathrm{d}}$} \\
\hline & & Incidence $^{b}(\%)$ & Severity $^{c}$ & Incidence $^{\mathrm{b}}(\%)$ & Severity & \\
\hline I 91/0067 & 50 & 0 & - & 0 & - & 38.0 \\
\hline I $91 / 2324$ & 48 & 0 & - & 0 & - & 243.2 \\
\hline I $91 / 2327$ & 50 & 0 & - & 0 & - & 150.0 \\
\hline I 95/0087 & 50 & 4.0 & 2.0 & 0 & - & 124.8 \\
\hline I $96 / 0036$ & 46 & 0 & - & 0 & - & 156.2 \\
\hline MM 97/2961 & 52 & 0 & - & 0 & - & 156.6 \\
\hline Nase 4 & 50 & 0 & - & 0 & - & 90.6 \\
\hline Nase 10 & 50 & 40.0 & 2.0 & 0 & - & 288.0 \\
\hline Nase 12 & 50 & 22.0 & 2.0 & 0 & - & 302.0 \\
\hline TME 14 & 48 & 64.0 & 2.0 & 0 & - & 347.4 \\
\hline TME 204 & 54 & 16.0 & 2.0 & 0 & - & 326.4 \\
\hline
\end{tabular}

a Elevation of the field at Mukono ZARDI is $1,185 \mathrm{~m}$.

b Percentage of total number of plants with CBSD (foliar) and CMD symptoms.

c Severity of CBSD foliar symptoms on scoring scale of 1 to $5: 1=$ no apparent symptoms; $2=$ slight foliar mosaic, no stem lesions; $3=$ foliar mosaic, mild stem lesions, no dieback; 4 = foliar mosaic, severe stem lesions, no dieback; 5 = defoliation, severe stem lesions, dieback.

${ }^{\mathrm{d}}$ Number of adult whiteflies on top five leaves of a representative shoot of a plant.

Table 2. Incidence and severity of cassava brown streak disease (CBSD), cassava mosaic disease (CMD), and whitefly numbers in the most predominant cultivars grown by farmers in Mukono, Wakiso, and Mayuge districts in Uganda

\begin{tabular}{|c|c|c|c|c|c|c|}
\hline \multirow{2}{*}{$\begin{array}{l}\text { Predominating cultivars } \\
\text { per district }\end{array}$} & \multirow[b]{2}{*}{ Fields sampled $^{\mathrm{a}}$} & \multicolumn{2}{|c|}{ CBSD (foliar) } & \multicolumn{2}{|c|}{ CMD } & \multirow[b]{2}{*}{ Adult whiteflie } \\
\hline & & Incidence & Severity & Incidence & Severity & \\
\hline \multicolumn{7}{|l|}{ Mayuge district } \\
\hline Ebwanateraka & 1 & 0 & - & 16.7 & 2.4 & 10.3 \\
\hline Kabwa & 1 & 0 & - & 100.0 & 3.0 & 1.7 \\
\hline Magana & 10 & 0 & - & 78.7 & 2.9 & 9.2 \\
\hline Mfumbachai & 1 & 0 & - & 100.0 & 2.5 & 0.5 \\
\hline Nase 2 & 2 & 0 & - & 65.1 & 2.6 & 1.3 \\
\hline Nase 3 & 7 & 0 & - & 23.3 & 2.5 & 4.3 \\
\hline Nase 12 & 2 & 0 & - & 0 & - & 30.5 \\
\hline Njule & 2 & 0 & - & 68.4 & 2.9 & 2.1 \\
\hline TME 14 & 2 & 0 & - & 0 & - & 154.4 \\
\hline Unnamed (local) & 2 & 0 & - & 65.7 & 3.1 & 6.1 \\
\hline Mean': Local & & 0 & - & 74.8 & 2.9 & 7.1 \\
\hline Resistant $^{\mathrm{c}}$ & & 0 & - & 22.6 & 2.5 & 30.9 \\
\hline Overall & & 0 & - & 52.2 & 2.8 & 17.4 \\
\hline \multicolumn{7}{|l|}{ Mukono district } \\
\hline$I 92 / 0057\left(1,200 \mathrm{~m}^{\mathrm{d}}\right)$ & 4 & $17.5^{\mathrm{e}}$ & 2.0 & 35.0 & 2.2 & 11.1 \\
\hline Kabwa & 4 & 0 & - & 77.5 & 2.6 & 62.5 \\
\hline Matooke & 5 & 0 & - & 31.3 & 2.8 & 23.1 \\
\hline Nase 12 & 1 & 0 & - & 0 & - & 8.4 \\
\hline Njule & 6 & 0 & - & 37.2 & 2.9 & 7.1 \\
\hline TME 14 & 3 & 0 & - & 17.8 & 2.1 & 8.7 \\
\hline TME 204 & 3 & 0 & - & 21.1 & 2.0 & 30.4 \\
\hline Unnamed (local) & 4 & 0 & - & 47.5 & 2.8 & 7.0 \\
\hline Mean': Local & & 0 & - & 46.3 & 2.8 & 30.8 \\
\hline Resistant ${ }^{\mathrm{c}}$ & & 6.4 & 2.0 & 23.3 & 2.1 & 15.5 \\
\hline Overall & & 2.3 & 2.0 & 37.9 & 2.5 & 25.2 \\
\hline \multicolumn{7}{|l|}{ Wakiso district } \\
\hline Bamunanika & 4 & 0 & - & 60.0 & 3.0 & 4.4 \\
\hline I 92/0057 & 9 & 0 & - & 27.8 & 2.5 & 41.7 \\
\hline Kameza & 1 & 0 & - & 100.0 & 3.7 & 57.1 \\
\hline Kirimumpale & 2 & 0 & - & 41.7 & 3.1 & 10.1 \\
\hline Njule & 1 & 0 & - & 86.7 & 3.3 & 8.5 \\
\hline$T M E 14$ & 4 & 0 & - & 0.8 & 2.2 & 50.4 \\
\hline$T M E 204\left(1,141 m^{\mathrm{d}}\right)$ & 3 & $5.6^{\mathrm{f}}$ & 2.0 & 7.8 & 2.0 & 13.8 \\
\hline Unnamed (local) & 5 & 0 & - & 54.7 & 2.9 & 16.6 \\
\hline Unnamed (resistant) & 1 & 0 & - & 3.3 & 2.0 & 19.6 \\
\hline Mean ${ }^{b}$ : Local & & 0 & - & 60.3 & 3.1 & 14.3 \\
\hline Resistant $^{\mathrm{c}}$ & & 1.0 & 2.0 & 16.5 & 2.4 & 37.5 \\
\hline Overall & & 0.6 & 2.0 & 35.4 & 2.7 & 27.5 \\
\hline
\end{tabular}

a Where many cultivars are grown in the same field, records were taken only on the predominant cultivar.

b Averages for all fields sampled per district.

c Officially developed CMD-resistant cultivars and corresponding statistics are indicated in italics.

d Elevation of farmers' fields were CBSD foliar symptoms were observed.

e One out of four fields of cultivar I 92/0057 in Mukono had plants showing CBSD foliar symptoms (incidence $=70 \%$ ).

${ }^{\mathrm{f}}$ One out of three fields of cultivar TME 204 in Wakiso had plants with CBSD foliar symptoms (incidence $=16.8 \%$ ). 
associated with CBSD, was seen in some plants (Fig. 1).

Incidences and severities of CBSD and CMD. Overall, chlorosis recorded as a severity score of 2 was the only aboveground CBSD symptom observed. The disease was present in the 8-month-old demonstration garden of CMD-resistant cultivars at Mukono ZARDI, at an elevation of 1,185 masl. Five of 11 cultivars at this site had plants with CBSD symptoms. The affected cultivars (and their respective CBSD incidences in brackets) were TME $14(64 \%)$, Nase $10(40 \%)$, Nase 12 (22\%), TME 204 (16\%), and I 95/0087 (4\%) (Table 1). At this site, CBSD was also present in two younger crops (4 months) of the cultivar TME 14, one planted nearby and the other just adjacent to the old planting (data not shown). CBSD was observed elsewhere in Mukono and Wakiso districts but was not found in Mayuge district. In Mukono district, CBSD was observed in one out of four farmers' fields planted with the CMD-resistant cultivar I 92/0057 (Table 2). The individual CBSD-affected farmer's field was at an elevation of 1,200 masl and had a CBSD incidence of $70 \%$. Cassava plants harvested from this field 4 months later had the root necrosis symptoms associated with CBSD.

In Wakiso district, CBSD was found in two out of three fields planted with the CMD-resistant cultivar TME 204. Mean incidence of CBSD (foliar) in TME 204 was $5.6 \%$ (Table 2). One of the affected fields planted with cultivar TME 204 was at an elevation of 1,141 masl and had a CBSD foliar incidence of $16.8 \%$. In the other field, affected plants had both root and foliar CBSD symptoms. Two out of 10 plants sampled had CBSD root symptoms. Ninety-two percent of the roots harvested from the affected plants were necrotic, and all CBSD-affected roots were severely damaged and averaged a severity score of 4. This field was located at an elevation of 1,156 masl.

Average CMD incidence for landraces was $60 \%$ (range 16.7 to $100 \%$ ), and that for resistant varieties was $20 \%$ (range 0 to $65 \%$ ) (Tables 2 and 3). Severity of CMD was generally moderate, with overall averages of 2.9 (range 2.5 to 3.7 ) and 2.3 (range 2.0 to 2.6) for landraces and resistant varieties, respectively (Tables 2 and 3 ). Presence of the Uganda variant of East African cassava mosaic virus (EACMV-UG) and African cassava mosaic virus (ACMV) in CMD-affected plants was confirmed using PCR with virus-specific primers, and most samples had single EACMV-UG infections (data not shown). Cassava mosaic begomoviruses were not detected in samples from CMD-free plants, including plants with only CBSD symptoms.

Whitefly populations. At Mukono ZARDI, mean whitefly numbers (per plant) on TME 14, TME 204, Nase 10, Nase 12, and I 91/2324 were generally greater than 200 (Table 1). The high populations had produced so much honeydew that black sooty mold was covering the lower leaves of many cassava plants, especially in cultivars TME 14, TME 204, I $91 / 2324$, and I 91/2327. In comparison to the observation at Mukono ZARDI, average numbers of whiteflies on cassava at farmers' fields in the three districts were moderate and did not exceed 30 (range 17 to 28) adult whiteflies per plant (Table 2). Both the highest and lowest populations of adult whiteflies colonizing a single cultivar on a farmer's field were recorded in Mayuge district on TME 14 and Mfumbachai, respectively. The numbers of whiteflies varied among the predominant cultivars assessed on farmers' fields, but this did not seem to be related to the level of resistance of the cultivars to CMD or the occurrence of CBSD among the cultivars (Table 3). The whiteflies colonizing cassava were not recorded to species level.

RT-PCR amplification with CBSVspecific primers and sequence comparisons. Using virus-specific primers, CBSV was detected in all eight leaf samples obtained from plants with CBSD symptoms at Mukono ZARDI, and also in all four samples from farmers' fields. An expected amplicon consisting of ca. $230 \mathrm{bp}$ was obtained from the symptomatic leaf samples (Fig. 2). The amplicons were not produced from leaf samples from the apparently healthy samples, although three of them (lanes 2, 3, and 6, Fig. 2) had faint bands the same size as the positive samples, suggesting that these three plants had latent CBSV infections at the time of sample collection. BLASTn (2) searches of GenBank and alignment of the nucleotide sequences obtained in this study with published CBSV sequences revealed that the CBSV-specific primers amplified a 222-bp fragment at the $3^{\prime}$ end of the CBSV coat protein $(\mathrm{CP})$ coding sequence. Analysis of sequences derived from the PCR amplicons indicated $>95 \%$ nucleotide sequence identity among the Ugandan CBSV isolates (Table 4). The 222-bp partial CP gene sequences of the Ugandan isolates were 77.0 to $78.5 \%$ identical to nucleotide sequences of CBSV isolates from Mozam-

Table 3. Mean incidence and severity of cassava brown streak disease (CBSD), cassava mosaic disease (CMD), and whitefly numbers recorded on cultivars commonly grown by farmers in Mayuge, Mukono, and Wakiso districts

\begin{tabular}{|c|c|c|c|c|c|c|c|}
\hline \multirow[b]{2}{*}{ Cultivar } & \multicolumn{2}{|c|}{ Number of plantings } & \multicolumn{2}{|c|}{ CBSD (foliar) } & \multicolumn{2}{|c|}{ CMD } & \multirow[b]{2}{*}{ Adult whiteflies } \\
\hline & Overall & Sampled $^{\mathbf{a}}$ & Incidence & Severity & Incidence & Severity & \\
\hline Bamunanika & 7 & 4 & 0 & - & 60.6 & 3.0 & 4.4 \\
\hline I 92/0057 & 25 & 13 & $5.4^{\mathrm{b}}$ & 2.0 & 31.6 & 2.4 & 18.0 \\
\hline Kabwa & 8 & 7 & 0 & - & 82.3 & 2.6 & 50.3 \\
\hline Kirimumpale & 4 & 3 & 0 & - & 41.6 & 3.1 & 10.1 \\
\hline Magana & 16 & 13 & 0 & - & 78.7 & 2.9 & 9.2 \\
\hline Matooke & 9 & 5 & 0 & - & 31.3 & 2.7 & 53.1 \\
\hline Nase 2 & 6 & 3 & 0 & - & 65.1 & 2.6 & 1.3 \\
\hline Nase 3 & 24 & 8 & 0 & - & 23.3 & 2.5 & 4.3 \\
\hline Nase 12 & 5 & 4 & 0 & - & 0.0 & - & 0.9 \\
\hline Njule & 26 & 10 & 0 & - & 49.6 & 3.0 & 6.2 \\
\hline TME 14 & 30 & 15 & 0 & - & 6.3 & 2.1 & 59.6 \\
\hline TME 204 & 13 & 6 & $2.8^{\mathrm{c}}$ & 2.0 & 14.4 & 2.0 & 22.1 \\
\hline Unnamed (local) ${ }^{\mathrm{d}}$ & 11 & 7 & 0 & - & 71.4 & 3.4 & 8.8 \\
\hline Other local $(n=13)^{\mathrm{e}}$ & 40 & 6 & 0 & - & 69.5 & 3.0 & 25.3 \\
\hline Other resistant $(n=4)^{\mathrm{f}}$ & 30 & 1 & 0 & - & 10.0 & 2.0 & 40.9 \\
\hline All local $(n=30)$ & 121 & 49 & 0 & - & 60.0 & 2.9 & 18.2 \\
\hline All resistant $(n=10)$ & 133 & 41 & 2.1 & 2.0 & 20.2 & 2.3 & 29.5 \\
\hline All cultivars $(n=40)$ & 254 & 90 & 1.0 & 2.0 & 41.8 & 2.7 & 23.4 \\
\hline
\end{tabular}

a Number of fields in which cultivar predominated in two or more fields.

${ }^{\mathrm{b}}$ One out of overall 13 fields of the cultivar I 92/0057 had plants showing CBSD foliar symptoms (incidence of 70\%).

c One out of overall six fields of the cultivar TME 204 had plants with CBSD foliar symptoms (incidence of $16.8 \%$ ).

${ }^{\mathrm{d}}$ Landraces for which farmers had no names.

e Landraces that predominated in one field.

f Officially developed CMD-resistant cultivars that predominated in one field. All CMD-resistant cultivars and corresponding statistics are indicated in italics. 
bique (MZ) and shared 77.9 to $82.9 \%$ identity with sequences of isolates from Tanzania (TZ) (Table 4). Partial CP nucleotide sequence identity among and between known Tanzanian and Mozambican CBSV isolates was $>94 \%$. Clustal W multiple alignment of the partial CBSV CP gene sequences of the isolates sequenced in this study indicated 85.1 to $90.5 \%$ amino acid (aa) identity among the isolates and 43.9 to $56.8 \%$ aa identity to corresponding parts of published CBSV sequences (Table 4).

\section{DISCUSSION}

When there are no previous records in a country or region of a disease that is subsequently found to be present at high incidences as was the case with CBSD in northern Mozambique in 1998 (34), it is impossible to know if the disease was previously present but unnoticed, or spread as the result of a recent introduction. Foliar and root symptoms, RT-PCR, and sequence data have confirmed the recent reemergence of CBSD in Uganda. There are several possibilities for the origin of the current outbreak of CBSD in Uganda. Firstly, that the disease might have been present for many years at a low level and was not noticed. It is known that CBSD was accidentally introduced into Uganda in the 1930s (12), but all cassava plants at the affected sites in Bukalasa and Serere were destroyed. In 1994, CBSD-like symptoms were observed on cassava plants in one field near Entebbe in central Uganda (33), but this was not confirmed and there have been no definitive reports since that time. A problem with surveys assessing the incidence of CBSD is that the expression of foliar symptoms varies with season and crop age. Young leaves commonly do not show any CBSD symptoms, whereas mature symptomatic leaves soon dry and drop off. A survey of Zanzibar conducted in 1994 concluded that the disease was absent from the island (16), although it had been observed there in the 1950s. However, when the island was surveyed again in 1998, CBSD was found to be prevalent (35). In addition, as confirmed by our results, CMD is endemic in areas where CBSD also occurs, and symptoms of $\mathrm{CMD}$ can mask the less conspicuous leaf symptoms of CBSD.

Viruses are capable of evolving in nature into more virulent forms. Therefore, it is possible that the re-emergence of CBSD in Uganda may be due to the emergence of a new and more aggressive strain of CBSV. Comparisons of partial (ca. 25\%) CP gene sequences obtained in this study with published CBSV CP sequences indicated 77 to $83 \%$ nucleotide and 44 to $57 \%$ aa identity, suggesting the Ugandan isolates to be sequence variants of CBSV. According to criteria recently suggested for classification of viruses in the family Potyviridae, $76 \%$ nucleotide sequence identity is optimal species demarcation threshold for fulllength CP (1). The sequences compared in this study are at the C-terminal region of CBSV CP, but the CP core region is known to be most conserved among Potyviridae (22). Although CP nucleotide sequence is reliable for estimation of identity of Potyviridae (1), the short length of sequences used in this study provides limited evidence for definitive conclusions. More precise classification will have to be based on sequences of substantial length, including full-length CP sequences as are widely used for diagnostic and taxonomic studies of Potyviridae (1). Another possibility is that there has been a recent introduction of infected material from the coastal areas of Kenya, Tanzania, Malawi, or Mozambique where CBSD is endemic. This argument seems reasonable to the extent that, in this study, CBSD was mainly observed in recently introduced cassava cultivars. Thus, it is also possible that the newly introduced genotypes are more susceptible to CBSD.

It is notable that the re-emergence of CBSD in central Uganda has coincided with generally high $B$. tabaci populations in the area. The spread of the recombinant variant, EACMV-UG, has been associated with a severe CMD pandemic that spread from Uganda to neighboring countries between 1988 and the present day $(5,6,14,25)$, and was linked to unusually high populations of $B$. tabaci $(4,15)$ which have persisted to date. Whitefly populations are known to fluctuate within and between seasons (26), and the periods of spread of CBSD at coastal Tanzania closely coincided with surges in whitefly populations (19). Little or no spread occurred in years such as 2002, when whiteflies were absent or present at levels rarely exceeding two to three per plant on the uppermost shoots. Therefore, whatever the

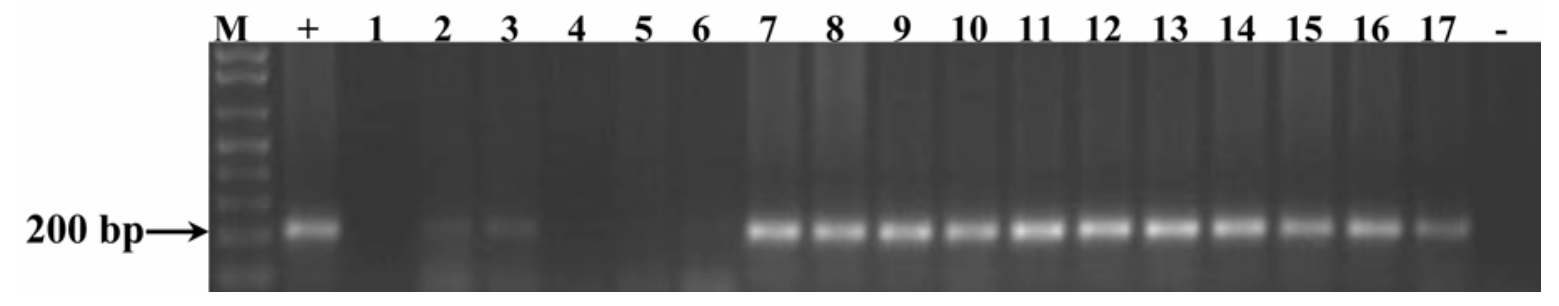

Fig. 2. Agarose gel electrophoresis of reverse transcription-polymerase chain reaction (RT-PCR)-amplified products (222-bp cassava brown streak virus coat protein gene fragment) using Cassava brown streak virus (CBSV)-specific primer pair CBSV 10F and CBSV 11R. RNA isolated from cassava brown streak disease (CBSD)-affected and apparently healthy cassava plants was used for cDNA synthesis. Lane $\mathrm{M}=1 \mathrm{~kb}+\mathrm{DNA}$ ladder; $+=$ positive control (isolate MKN from cultivar TME 14); lanes 1 to $3=$ apparently healthy cassava plants at Mukono ARDC; lanes 4 to $6=$ apparently healthy cassava plants at farmers' fields in Mukono and Wakiso districts; lanes 7 to $13=$ cassava plants showing typical CBSD foliar symptoms at Mukono ZARDI; lanes 14 to $17=$ cassava plants showing typical CBSD foliar symptoms at farmers' fields in Mukono and Wakiso districts; - = negative control (glasshouse-grown CBSV-free cassava plant).

Table 4. Percent partial coat protein (CP) gene nucleotide (above diagonal) and amino acid (below diagonal) sequence identity among Cassava brown streak virus (CBSV) isolates ${ }^{a}$

\begin{tabular}{|c|c|c|c|c|c|c|c|c|c|}
\hline CBSV isolate & MKN $^{b}$ & NAM $^{b}$ & $\mathbf{W K S}^{\mathbf{b}}$ & $M Z 1$ & $M Z 2$ & $T Z A$ & $T Z B$ & $T Z C$ & $T Z P$ \\
\hline $\mathrm{MKN}^{\mathrm{b}}$ & - & 96.4 & 95.9 & 78.5 & 78.5 & 81.1 & 82.9 & 81.5 & 82.4 \\
\hline NAM $^{b}$ & 85.1 & - & 99.5 & 78.0 & 78.0 & 78.8 & 80.6 & 80.5 & 78.8 \\
\hline $\mathrm{WKS}^{\mathrm{b}}$ & 85.1 & 90.5 & - & 77.0 & 77.0 & 77.9 & 79.7 & 79.5 & 77.9 \\
\hline$M Z 1$ & 45.5 & 45.5 & 43.9 & - & 100.0 & 98.5 & 95.5 & 96.0 & 95.5 \\
\hline$M Z 2$ & 45.5 & 45.5 & 43.9 & 93.9 & - & 98.5 & 95.5 & 96.0 & 95.5 \\
\hline$T Z A$ & 51.4 & 47.3 & 45.9 & 90.9 & 90.9 & - & 95.0 & 97.0 & 95.9 \\
\hline$T Z B$ & 56.8 & 55.4 & 54.1 & 81.8 & 81.8 & 82.4 & - & 94.5 & 94.6 \\
\hline$T Z C$ & 47.0 & 47.0 & 45.5 & 84.8 & 84.8 & 84.8 & 77.3 & - & 94.5 \\
\hline$T Z P$ & 55.4 & 48.6 & 48.6 & 83.3 & 83.3 & 85.1 & 79.7 & 78.8 & - \\
\hline
\end{tabular}

${ }^{a}$ Nucleotide and amino acid sequence identities are presented for cDNA representing 222-bp CP gene fragment amplified by primers used in this study, including homologous regions of published CP gene sequences of CBSV isolates from Mozambique (MZ) and Tanzania (TZ) (indicated in italics).

${ }^{\mathrm{b}}$ Isolates sequenced in this work: MKN (DQ837302), NAM (DQ837303), and WKS (DQ837304). 
cause of the current outbreak of CBSD, the elevated whitefly numbers in Uganda may be aiding the spread of the disease.

Nichols (24) believed that CBSD rarely occurred at altitudes above $1,000 \mathrm{~m}$ because low temperature induced severe symptoms in plants grown from CBSD-infected cuttings and such plants did not survive. However, Jennings (13) examined plants grown from CBSD-infected cuttings at $1,500 \mathrm{~m}$ and $1,700 \mathrm{~m}$ in Tanzania and found that most of the plants continued to grow well despite showing symptoms of CBSD on leaves and roots. Their results also showed that there had been no spread of the disease to neighboring cassava plants, indicating that vector transmission of CBSD did not occur at higher altitudes. If it is the case that Tanzanian populations of $B$. tabaci are unable to transmit CBSV at high altitude, then it is possible that biological changes in the whiteflies associated with the CMD pandemic in Uganda have influenced their ability to transmit plant viruses, including CBSV. Similarly, changes in weather, especially the frequent occurrence of unusually prolonged hot and dry seasons in recent years, may have enhanced the re-emergence of CBSD or CBSV transmission by whiteflies in Uganda, irrespective of changes in the population and type of $B$. tabaci. One factor contributing to the lack of spread of CBSD inland might be the spatial separation of the main cassava growing areas on the coast of Eastern Africa from those further inland by large regions where food staples include other crops such as sorghum and millet, and cassava is rarely grown.

The reappearance of CBSD in Uganda raises great concern for food production and monetary income for the country and the entire region. As observed in this study, farmers in the region still predominantly grow landraces, which already commonly suffer from CMD and resultant high loss in yield. There is an urgent need for an extensive survey of CBSD in Uganda and development of phytosanitary and regulatory measures to restrict its further spread. Additionally, the emergence of CBSD in Uganda has implications for the movement of cassava germ plasm in the region. Particularly, it is appropriate that the practice of movement of cassava germ plasm between countries in the region through the open quarantine system is revisited in favor of exchange of virus-indexed tissue culture plantlets. This will require establishment of rapid and robust CBSV diagnostics capability within the different countries in the region. For long-term control, development and deployment of control measures including cultivars with resistance to CBSD, $\mathrm{CMD}$, and whiteflies should be a priority following the current confirmation of CBSD at altitudes above $1,000 \mathrm{~m}$.

\section{ACKNOWLEDGMENTS}

This publication is an output from research projects funded by the UK Department for International
Development (DFID), Projects R8227 and R8303, Crop Protection Programme (CPP), and the Ugandan National Agricultural Research Organisation (NARO). The PCR and sequence determination of the amplicons was done in the laboratory of Dr. Claude Fauquet (ILTAB, Donald Danforth Plant Science Center, St. Louis, MO, USA) where the first author visited, and we thank Dr. Jitender Yadav for his input.

\section{LITERATURE CITED}

1. Adams, M. J., Antoniw, J. F., and Fauquet, C. M. 2005. Molecular criteria for genus and species discrimination within the family Potyviridae. Arch. Virol. 150:459-479.

2. Altschul, S. F., Madden, T. L., Schaffer, A. A., Zhang, J., Zhang, Z., Miller, W., and Lipman, D. J. 1997. Gapped BLAST and PSI-BLAST: A new generation of protein database search programs. Nucleic Acids Res. 25:3389-3402.

3. Bock, K. R. 1994. Studies on cassava brown streak disease in Kenya. Trop. Sci. 34:134-145.

4. Colvin, J., Omongo, C. A., Maruthi, M. N., Otim-Nape, G. W., and Thresh, J. M. 2004. Dual begomovirus infections and high Bemisia tabaci populations: Two factors driving the spread of a cassava mosaic disease pandemic. Plant Pathol. 53:577-584.

5. Deng, D., Otim-Nape, G. W., Sangare, A., Ogwal, S., Beachy, R. N., and Fauquet, C. M. 1997. Presence of a new virus closely related to East African cassava mosaic geminivirus, associated with cassava mosaic outbreak in Uganda. Afr. J. Root Tuber Crops 2:23-28.

6. Gibson, R. W., Legg, J. P., and Otim-Nape, G. W. 1996. Unusually severe symptoms are a characteristic of the current pandemic of mosaic virus disease of cassava in Uganda. Ann. Appl. Biol. 128:479-490.

7. Gondwe, F. M. T., Mahungu, N. M., Hillocks, R. J., Raya, M. D., Moyo, C. C., Soko, M. M., Chipungu, F., and Benesi, I. R. M. 2003. Economic losses experienced by small-scale farmers in Malawi due to cassava brown streak virus disease. Pages 28-35 in: Cassava Brown Streak Virus Disease: Past, Present and Future. J. P. Legg and R. J. Hillocks, eds. Proc. Int. Workshop, Mombasa, Kenya, 27-30 October 2002. Natural Resources International Limited, Aylesford, UK.

8. Hillocks, R. J., and Jennings, D. L. 2003. Cassava brown streak disease: A review of present knowledge and research needs. Int. J. Pest Manag. 49:225-234.

9. Hillocks, R. J., Raya, M. D., and Thresh, J. M. 1996. The association between root necrosis and above-ground symptoms of brown streak virus infection of cassava in southern Tanzania. Int. J. Pest Manag. 42:285-289.

10. Hillocks, R. J., Raya, M. D., and Thresh, J. M. 1999. Distribution and symptom expression of cassava brown streak disease in southern Tanzania. Afr. J. Root Tuber Crops 3:57-61.

11. Hillocks, R. J., Thresh, J. M., Tomas, J., Botaos, M., Macia, R., and Zavier, R. 2002. Cassava brown streak disease in northern Mozambique. Int. J. Pest Manag. 48:179-182.

12. Jameson, J. D. 1964. Cassava mosaic disease in Uganda. E. Afr. Agric. J. 30:208-213.

13. Jennings, D. L. 1960. Observations on virus diseases of cassava in resistant and susceptible varieties. II. Brown streak disease. Emp. J. Exp. Agric. 28:261-269.

14. Legg, J. P. 1999. Emergence, spread and strategies for controlling the pandemic of cassava mosaic virus disease in east and central Africa. Crop Prot. 18:627-637.

15. Legg, J. P., and Ogwal, S. 1998. Changes in the incidence of African cassava mosaic virus disease and the abundance of its whitefly vector along south-north transects in Uganda. J. Appl. Entomol. 122:169-178.

16. Legg, J. P., and Raya, M. D. 1998. Survey of virus diseases in Tanzania. Int. J. Pest Manag. $44: 17-23$.
17. Lodhi, M. A., Ye, G. N., Weeden, N. F., and Reisch, B. 1994. A simple and efficient method for DNA extraction from grapevine cultivars and Vitis species. Plant Mol. Biol. Rep. 12:6-13.

18. Mahungu, N. M., Bidiaka, M., Tata, H., Lukombo, S., and N'luta, S. 2003. Cassava brown streak disease-like symptoms in Democratic Republic of Congo. Roots 8:8-9.

19. Maruthi, M. N., Hillocks, R. J., Mtunda, K., Raya, M. D., Muhanna, M., Kiozia, H., Rekha, A. R., Colvin, J., and Thresh, J. M. 2005 Transmission of Cassava brown streak virus by Bemisia tabaci (Gennadius). J. Phytopathol. 153:307-312.

20. Monger, W. A., Seal, S., Cotton, S., and Foster, G. A. 2001. Identification of different isolates of cassava brown streak virus and development of a diagnostic test. Plant Pathol. 50:768-775.

21. Monger, W. A., Seal, S., Isaac, A. M., and Foster, G. D. 2001. Molecular characterisation of the cassava brown streak virus coat protein. Plant Pathol. 50:527-534.

22. Monger, W. A., Spence, N. J., and Foster, G. D. 2001. Molecular evidence that the aphidtransmitted Tomato mild mottle virus belongs to the Potyviridae family but not the Potyvirus genus. Arch. Virol. 146:2435-2441.

23. Muga, T., and Thresh, J. M. 2002. Incidence of cassava mosaic and cassava brown streak virus diseases in coastal Kenya. Roots 8:12-14.

24. Nichols, R. F. W. 1950. The brown streak disease of cassava: Distribution, climatic effects and diagnostic symptoms. E. Afr. Agric. J. 15:154-160.

25. Otim-Nape, G. W., Alicai, T., and Thresh, J. M. 2001. Changes in the incidence and severity of cassava mosaic virus disease, varietal diversity and cassava production in Uganda. Ann. Appl. Biol. 138:313-327.

26. Seif, A. A. 1981. Seasonal fluctuations of adult population of the whitefly, Bemisia tabaci on cassava. Insect Sci. Appl. 1:363-364.

27. Shaba, E. R., Chipungu, F., and Mazuma, E. D. L. 2003. Cassava Brown Streak Virus Disease in Malawi: Pages 18-19 in: Cassava Brown Streak Virus Disease: Past, Present and Future. J. P. Legg and R. J. Hillocks, eds. Proc. Int. Workshop, Mombasa, Kenya, 27-30 October 2002. Natural Resources International Limited, Aylesford, UK.

28. Storey, H. H. 1936. Virus diseases of East African plants: VI A progress report on studies of the diseases of cassava. E. Afr. Agric. J. 2:34-39.

29. Storey, H. H. 1939. 1939 Report of the Plant Pathologist. East African Agricultural Research Station. p. 9

30. Terry, E. R., and Hahn, S. K. 1980. The effect of cassava mosaic disease on growth and yield of a local and an improved variety of cassava. Trop. Pest Manag. 26:34-37.

31. Thompson, J. D., Higgins, D. G., and Gibson, T. J. 1994 CLUSTAL W: Improving the sensitivity of progressive multiple sequence alignment through sequence weighting, position specific gap penalties and weight matrix choice. Nucleic Acids Res. 22:4673-4680.

32. Thresh, J. M. 2003. Brief history of cassava brown streak virus disease. Pages 5-6 in: Cassava Brown Streak Virus Disease: Past, Present and Future. J. P. Legg and R. J. Hillocks, eds. Proc. Int. Workshop, Mombasa, Kenya, 27-30 October 2002. Natural Resources International Limited, Aylesford, UK.

33. Thresh, J. M., Fargette, D., and Otim-Nape, G. W. 1994. The viruses and virus diseases of cassava in Africa. Afr. Crop Sci. J. 24:459-478.

34. Thresh, J. M., and Hillocks, R. J. 2003. Cassava mosaic and cassava brown streak diseases in Nampula and Zambezia Provinces of Mozambique. Roots 8:10-15.

35. Thresh, J. M., and Mbwana, M. W. 1998. Cassava mosaic and cassava brown streak virus diseases in Zanzibar. Roots 5:6-8. 